\title{
ВMJ Global Health Understanding the determinants of infant and under-five mortality rates: a multivariate decomposition analysis of Demographic and Health Surveys in Ghana, 2003, 2008 and 2014
}

\author{
Duah Dwomoh, ${ }^{\oplus 1}$ Susan Amuasi, ${ }^{2}$ Kofi Agyabeng, ${ }^{3}$ Gabriel Incoom, ${ }^{4}$ \\ Yakubu Alhassan, ${ }^{3}$ Alfred Edwin Yawson ${ }^{5}$
}

To cite: Dwomoh D,

Amuasi S, Agyabeng K, et al. Understanding the determinants of infant and under-five mortality rates: a multivariate decomposition analysis of Demographic and Health Surveys in Ghana, 2003, 2008 and 2014. BMJ Global Health 2019;4:e001658. doi:10.1136/ bmjgh-2019-001658

Handling editor Sanni Yaya

- Additional material is published online only. To view please visit the journal online (http://dx.doi.org/10.1136/ bmjgh-2019-001658).

Received 23 April 2019 Revised 12 June 2019 Accepted 15 June 2019

Check for updates

(c) Author(s) (or their employer(s)) 2019. Re-use permitted under CC BY-NC. No commercial re-use. See rights and permissions. Published by BMJ.

For numbered affiliations see end of article.

Correspondence to Dr Duah Dwomoh; duahdwomoh@yahoo.com

\section{ABSTRACT}

Introduction Despite the decline in infant and underfive mortality rates since the last decade, Ghana did not meet the millennium development goal (MDG) 4 target. To implement effective interventions that could fast-track progress towards achieving the sustainable development goal 3 in 2030, factors contributing to the decline in child mortality throughout the MDG period and which factor(s) has/have been consistent in affecting child survival in the last decade need to be understood.

Methods This study used Demographic and Health Surveys (DHS) from 2003, 2008 and 2014 and data from World Bank Development Indicators (2000-2018). We employed modified Poisson with robust SE and multivariate decomposition approach to assess risk factors of child mortality using DHS data from 2003, 2008 and 2014. Penalised regression was used assess the effect of 25 country-level contextual factors on child survival. Results The risk of infant mortality is approximately five times higher among mothers who had multiple births compared with mothers who had single birth over the last decade (adjusted relative risk 4.6, 95\% $\mathrm{Cl} 3.2$ to 6.6 , $\mathrm{p}<0.001)$. An increase in the annual percentage of female labour force participation (FLFP) is associated with the reduction of approximately 10 and 18 infant and under-five annual deaths per 1000 live births, respectively.

Conclusions This study found that multiple births and shorter birth spacing are associated with increased risk of infant and under-five deaths over the last decade. Increased in FLFP, and the proportion of children sleeping under bed-net are associated with reduced risk of both infants and under-five deaths.

\section{BACKGROUND}

Many regions in sub-Saharan Africa (SSA) made little progress towards attaining the millennium development goal 4 (MDG4) which was aimed at reducing global underfive mortality rate (U5MR) by two-thirds between 1990 and $2015 .^{1}$ It is emphasised

\section{Key questions}

What is already known?

- Some of the factors associated with child survival have been identified in Ghana using either one-time point survey data or data that originate from a single health facility.

What are the new findings?

- The decline in infant and under-five mortality rates (U5MRs) in Ghana could be attributed to an increase in the proportion of children who slept under a bednet.

- Increasing the percentage of the female population ages 15 and older who are economically active is associated with a significant reduction in both infant and U5MRs in Ghana.

- Multiple births and children born with a shorter birth interval (less than 24 months) are at higher risk of child mortality.

What do the new findings imply?

- The government should focus more on policies that increase the percentage of female labour force participation.

- There should be continuous education for pregnant women on the multiplicity of risk associated with having multiple births and how to prepare for such births to reduce child mortality.

- The Ministry of Health and the Ghana Health Service should have a policy brief and specific scheduled training of health professionals on how to handle multiple births and associated risk especially during antenatal, delivery and postnatal care.

that only 12 countries in the WHO's, African Region met the MDG4. ${ }^{1}$ Although Ghana is not among these 12 countries, it is among the SSA countries that have taken pragmatic steps to reduce the prevalence of infant and under-five mortality deaths. Ghana has seen a progressive reduction in under-five deaths 
from 155 to 49.3 per 1000 live births between 1990 and 2017. ${ }^{2}$ The infant mortality rate (IMR) in Ghana has reduced from 79.3 per 1000 live births in 1990 to 35.7 per 1000 live births in 2017 representing a percentage reduction of approximately $55 \%$ over the period. In order to continue making progress in all-cause child mortality in Ghana and to meet the set target of the sustainable development goal 3 (SDG 3), there is the need to understand the multifaceted and complex causes of infant and under-five deaths. ${ }^{3}$

Admittedly, some studies in Ghana have assessed factors associated with child mortality. ${ }^{4-6}$ These studies relied on one-time point survey data. ${ }^{56}$ For studies that utilised only one-time point survey data, it becomes difficult to observe the trend and to identify factors that have been consistent in influencing child mortality. Using trend analysis to identify key factors associated with child mortality has become relevant for targeted intervention. The generalisability of some findings from previous studies was limited as most studies in Ghana restricted their analysis to only some selected districts ${ }^{7-9}$ or a few hospitals. ${ }^{10-12}$ For studies that pooled data from a different survey, it was not clear how they accounted for sampling weight from different surveys at different time points. The normalised weight in most complex surveys such as the Demographic and Health Surveys (DHS) is a relative weight which is valid for estimating means, proportions and ratios, ${ }^{13}$ but not valid for estimating totals, and may not be valid for pooled data from different surveys. ${ }^{14}$

To our knowledge, none of the previous studies in Ghana examined the extent to which each selected indicator contributed to the observed reduction in infant and U5MRs between two specific surveys. In addition, this remains the first study in Ghana that has simultaneously studied the impact of individual and country level characteristics on child survival. Finally and for targeted intervention, the application of modified Poisson based multivariate decomposition analysis provides a way to analyse differences in the child mortality between two points of time and the technique identifies factors that contribute to the observed reduction in child mortality. The findings from this study could critically inform policies and programmes aimed at reducing infant and U5MRs as the country is making an effort to achieve SDG 3.

\section{METHODS}

\section{Patient and public involvement}

Patients were not involved in this study.

\section{Data source}

The study used data from the three Ghana Demographic and Health Surveys (GDHS) conducted in Ghana, in 2003, 2008 and 2014. Data were downloaded from the DHS website (http://dhsprogram.com) after been granted permission. The DHS include the full birth history of all women within the reproductive age (15-49 years). The birth history includes all children born alive and their survival status to women of reproductive age (15-49 years). The children data file were merged with household data to obtain a complete dataset required for the analysis. The unit of analysis in this study is the children of women born in the last 5 years (0-59 months) preceding the survey. Online supplementary table S1 presents information on the three surveys included in this analysis.

\section{Sampling design used in the GDHS}

Each specific survey data sample was obtained using multistage stratified cluster sampling. Ghana has 10 administrative regions. Each region was stratified into urban and rural areas, yielding 20 sampling strata. Samples of enumeration areas (EAs) were selected independently in each stratum in two stages. The EA size is basically the number of residential households residing in a particular EA. In the first stage, stratification and proportional allocation are conducted at each of the lower administrative levels by sorting the sampling frame within each sampling stratum before sample selection using a probability proportional to size selection at the first stage of sampling. The second stage involves the selection of a fixed number of approximately 20-30 households per cluster selected with an equal probability systematic selection from the newly created household listing. Details of the sampling design for the GDHS can be obtained from the DHS programme website (www.dhsprogramme.com) or from the Ghana Statistical Service. ${ }^{15}$

\section{Outcome measures}

This study investigated two primary outcome measures: infant and U5MRs in Ghana. The IMR is the number of deaths in the first year of life (per 1000 live births) and measures the probability of dying before a child's first birthday. The U5MR measures the probability of death before a child's fifth birthday. Both IMR and U5MR were estimated within 5 years preceding the survey, including those born exactly 5 years before the survey. This study used information about the year of child's birth, whether each child was alive at the time of the survey, and how old a child was if $\mathrm{s} /$ he died to define the primary outcome measures. Specifically, a child who was born in the 5 years preceding the survey but unfortunately died within the first year of life was classified as infant death and coded as 1 or 0 otherwise. All deaths that occurred in the 5 years preceding the survey were classified as under-five death and they were respectfully coded as 1 or 0 otherwise. The unit of analysis in this study is all children born in the 5 years preceding each survey.

\section{Covariates from the GDHS data}

The choice of the selected covariates in determining infant and under-five mortality were adapted from the analytical framework for the study of child survival in developing countries by Mosley and Chen. ${ }^{16}$ 
This study examined the determinants of IMR and U5MR at four different levels of indicators: characteristics of the household (sex of the household head, age of the household head, household size, place of residence, region, household wealth, household access to improved water and sanitation), maternal characteristics (mothers age childbirth, marital status, highest educational level and body mass index), child indicators (age of the child, sex of the child, multiple birth, birth order and preceding birth interval) and finally, the maternal and delivery care received along with coverage of other interventions that could affect both IMR and U5MR (place of delivery, tetanus injection, antenatal care (ANC) attendance and valid national health insurance card).

\section{Country-level indicators}

Twenty-five indicators at the country level were also assessed to examine their effect on infant and underfive mortality. These indicators have been assessed previously. ${ }^{17}$ Our analysis was restricted to 25 indicators out of the 70 indicators previously studied because of lack of data on some covariates. Data were obtained from the World Bank Data Catalogue ${ }^{2}$ (online supplementary table S8 shows the country-level indicators that were studied).

\section{Statistical analysis of the DHS data}

The analysis adjusted for the complex survey design structure (clustering, stratification and weighting) to reduce bias and improve the precision of our estimates. Since the study pooled complex survey data from different surveys at different time points, the women/children standard weight were de-normalised. This was achieved by dividing the women standard weight by the women survey sampling fraction, that is, the ratio of a total number of women aged 15-49 years interviewed in the survey year over the total number of women aged 15-49 years in the country at the time of the survey. The total number of women aged 15-49 interviewed in the survey year was obtained from the DHS datasets, while the total number of women aged 15-49 years in the country at the time of the survey were obtained from OurWorldinData. ${ }^{18}$ The de-normalised women sampling weight is given by:

$$
\frac{\Psi \times \phi_{15-49}}{\phi_{15-49}^{S}}
$$

where $\Psi$ is the women sampling weight as estimated in the DHS, $\phi_{15-49}$ is the total females aged 15-49 in the country at the time of the survey and $\phi_{15-49}^{S}$ is the number of women age 15-49 interviewed in the survey.

Four different levels of statistical analysis were conducted to address the aforementioned research questions. First, the Rao-Scott $\chi^{2}$ test and the log-rank test that follows the Kaplan Meier procedure were used to test association and differences in mortality, test homogeneity of these groups and test for equality of survivor functions. Second, modified Poisson with the robust SE was used to assess the relationship between IMR, U5MR and all explanatory variables specifying the time at risk in every Poisson model that was fitted. Poisson was used in the analysis since the primary estimate of interest was a relative risk instead of HR from the Cox-proportional Model. That notwithstanding, a sensitivity analysis using was Cox-proportional Model was conducted to determine whether the results obtained were robust to the model specification. Finally, we applied weighted modified Poisson based multivariate decomposition technique ${ }^{19}$ which is comparable to the Oaxaca-Binder Method $^{20}$ but provides flexibility to use non-linear models to assess factors contributing to the decline in child mortality. Multivariate decomposition provides a way to analyse factors that contribute to the differences in mortality rates between two points of time: 2003-2008, 2008-2014 and 2003-2014. ${ }^{3}$

\section{Statistical analysis: assessing the impact of country-level indicators on infant and U5MRs in Ghana: 2000-2018}

To determine country-level contextual factors associated with infant and under-five mortality, this study employed theory-driven rigorous penalisation of the ordinary least square estimate with least absolute shrinkage and selection operator (LASSO) and square-root LASSO as proposed by Belloni et al. ${ }^{21}$ Rigorous penalisation is a modified version of the well-known LASSO.$^{22}$ The use of rigorous penalisation became necessary because of the high dimensionality of the data set (25 covariates investigated compared with sample size of 18) and the ability of the theory-driven penalisation for lasso and square-root to allow for heteroskedasticity, cluster-dependent and non-Gaussian errors.

Sensitivity analysis was conducted using two other different approaches for selecting the penalisation parameters: information criteria (implemented in lasso2), K-fold cross-validation for cross-section, panel and time-series data. The sensitivity analysis was to determine whether our results were robust to the different ways of selecting the penalisation parameters and to identify which indicator(s) will be selected by all the different penalisation procedure. Post-estimation ordinary least square was performed to address the shrinkage bias associated with estimates from rigorous penalisation. The LASSO procedure is implemented in Stata via lassopack; a collection of programme for regularised regression in Stata developed by Ahrens et al. ${ }^{23}$ All analyses were performed using Stata V.15 and a $\mathrm{p}$ value $<0.05$ was considered statistically significant.

\section{RESULTS}

The characteristics of the household, mother, child characteristics and coverage of health interventions that could influence infant and under-five mortality, among children born in the 5 years preceding the survey, Ghana 2003, 2008, 2014 and the pooled data (2003-2014).

A total of 12720 children born in the 5 years preceding each survey and 20003 women were included in the analysis. Three-fourth of the study population has males as their household head with an overall average 
age of 40.2 years (online supplementary table S2). The percentage of children born into households with access to improved sources of drinking water has increased over the last decade (GDHS 2003 $=75.9 \%$, GDHS $2008=86.0 \%$ and GDHS 2014=89.5\%; online supplementary table S2). The percentage of children born into a household with access to improved sanitation declined in 2008 but increased slightly in 2014 (GDHS 2003=9.6\%, GDHS $2008=7.5 \%$ and GDHS 2014 $=11.5 \%$; online supplementary table S2). The percentage of children born in rural households declined from $66.9 \%$ in 2003 to $55.0 \%$ in 2014 (online supplementary table S2). The percentage of children born in a household with less than five residents increased marginally from $34.1 \%$ to $37.2 \%$ (online supplementary table S2).

Mother's age at childbirth was 30.3 years with approximately $74.0 \%$ aged $18-34$ years (online supplementary table S3). The overall proportion of children born to mothers with tertiary education was $2.8 \%$ although there has been an increase over the period (GDHS 2003=1.1\%, GDHS 2008 $=2.4 \%$ and GDHS 2014 $=4.5 \%$; online supplementary table S3). Approximately $88.0 \%$ of children were born to mothers who were married or in a union (online supplementary table S3). The average age of the children was 2.3 years and the proportion of female children in the data set was $48.4 \%$ with $95.5 \%$ all births being single birth (online supplementary table S4). Approximately $10.0 \%$ of the mothers had given birth in less than 2 years between the previous and the current birth (online supplementary table S4). More than half $(57.3 \%)$ of the women attended four or more ANC and $40.0 \%$ received 2+tetanus injection (online supplementary table S5). Facility delivery has increased from $45.6 \%$ in 2003 to $73.0 \%$ in 2014 (online supplementary table S5). The number of children that slept under bednet also increased from 16.2\% in 2003 to $50.7 \%$ in 2014 (online supplementary table S5).

\section{Levels, trend and difference in infant and U5MRs between surveys}

The IMR in 2003 was 64 per 1000 live births but declined to 50 per 1000 live births in 2008 and 41 per 1000 live births in 2014. Thus IMR declined by 14 per 1000 live births between 2003 and 2008, 23 per 1000 live birth between 2003 and 2014 and only decline marginally by 9 per 1000 live births between 2008 and 2014 (online supplementary table S6). The U5MR in 2003 was 111 per 1000 live births and declined to 80 per 1000 live births in 2008 and further declined to 60 per 1000 live births in 2014. This resulted in the drastic reduction in U5MR by 51 per 1000 live births between 2003 and 2014 (online supplementary table $\mathrm{S} 7$ ).

\section{Results on the determinants of factors associated with infant mortality in 2003, 2008, 2014 and 2003-2014 combined: modified Poisson with robust SE}

The risk of infant mortality from multiple births reduced to 3.5 in the 2008 GDHS (adjusted relative risk; $\mathrm{aRR}=3.5$,
$95 \%$ CI 1.6 to $7.7, \mathrm{p}<0.01$; table 1 ) but increased to approximately five times as high as the risk of single birth in the 2014 GDHS $(\mathrm{aRR}=4.6,95 \%$ CI 2.4 to 8.6, $\mathrm{p}<0.01$; table 1 ). The pooled analysis revealed that all children born to mothers who had multiple births between 1999 and 2014 were 4.6 times as likely to experience infant mortality compared with children born to mothers who had single birth (source: 2003-2014 GDHS, aRR=4.6, $95 \%$ CI 3.2 to $6.6, \mathrm{p}<0.001$; table 1$)$. Children who slept under mosquito bednet was associated with 40\%-50\% reduction in the risk of infant mortality in 2003, 2008, 2014 and the pooled data (1999-2014) $(\mathrm{p}<0.05$; table 1$)$.

Although the effect was unadjusted since data was restricted to only most recent birth reducing the sample size considerably, the optimal birth interval, 24-35 months was associated with $40 \%$ reduction in the risk of infant mortality compared with the birth interval of fewer than 2 years (source: 2003-2014 GDHS, aRR=0.6, 95\% CI 0.5 to $0.8, \mathrm{p}<0.01$, table 1$)$. A similar effect of the covariates on infant mortality was observed when a sensitivity analysis was conducted by estimating the HR from the Cox-proportional hazard model (table 1).

\section{Results on the determinants of factors associated with under- five mortality in 2003, 2008, 2014 and 2003-2014 combined: modified Poisson with robust SE}

Children born to mothers who had multiple births were approximately five times as likely to die within the 59 months of birth compared with children born to mothers who had single birth (source: 2003 GDHS, aRR $=5.2,95 \%$ CI 3.2 to $8.6, \mathrm{p}<0.001$; table 2 ). The risk of under-five mortality from multiple births reduced to 3.4 in the 2008 GDHS (aRR=3.4, 95\% CI 1.6 to 7.1, $\mathrm{p}<0.01$; table 2$)$ but increased to approximately five times as high as the risk of single birth in the 2014 GDHS (aRR=4.7, 95\% CI 2.6 to $8.5, \mathrm{p}<0.01$; table 2 ).

The pooled analysis revealed that all children born to mothers who had multiple births between 1999 and 2014 were 4.3 times as likely to experience under-five mortality compared with children born to mothers who had single birth (source: 2003-2014 GDHS, aRR=4.3, 95\% CI 3.1 to $6.1, \mathrm{p}<0.001$; table 2). Distribution of bednet has contributed to the reduction of under-five mortality. Children who slept under mosquito bednet was associated with $40 \%-50 \%$ reduction in the risk of U5M in 2003, 2008, 2014 and the pooled data (1999-2014) $(\mathrm{p}<0.05$; table 2).

Although the effect was unadjusted since data was restricted to only most recent birth reducing the sample size considerably, the optimal birth interval, 24-35 months was associated with $4 \%$ reduction in the risk of under-five mortality compared with the birth interval of fewer than 2 years (2003-2014 GDHS, aRR $=0.6$, 95\% CI 0.5 to $0.9, \mathrm{p}<0.01$, table 2 ). A similar effect of the covariates on under-five mortality was observed when a sensitivity analysis was conducted by estimating the HR from the Cox-proportional hazard model (table 2). 


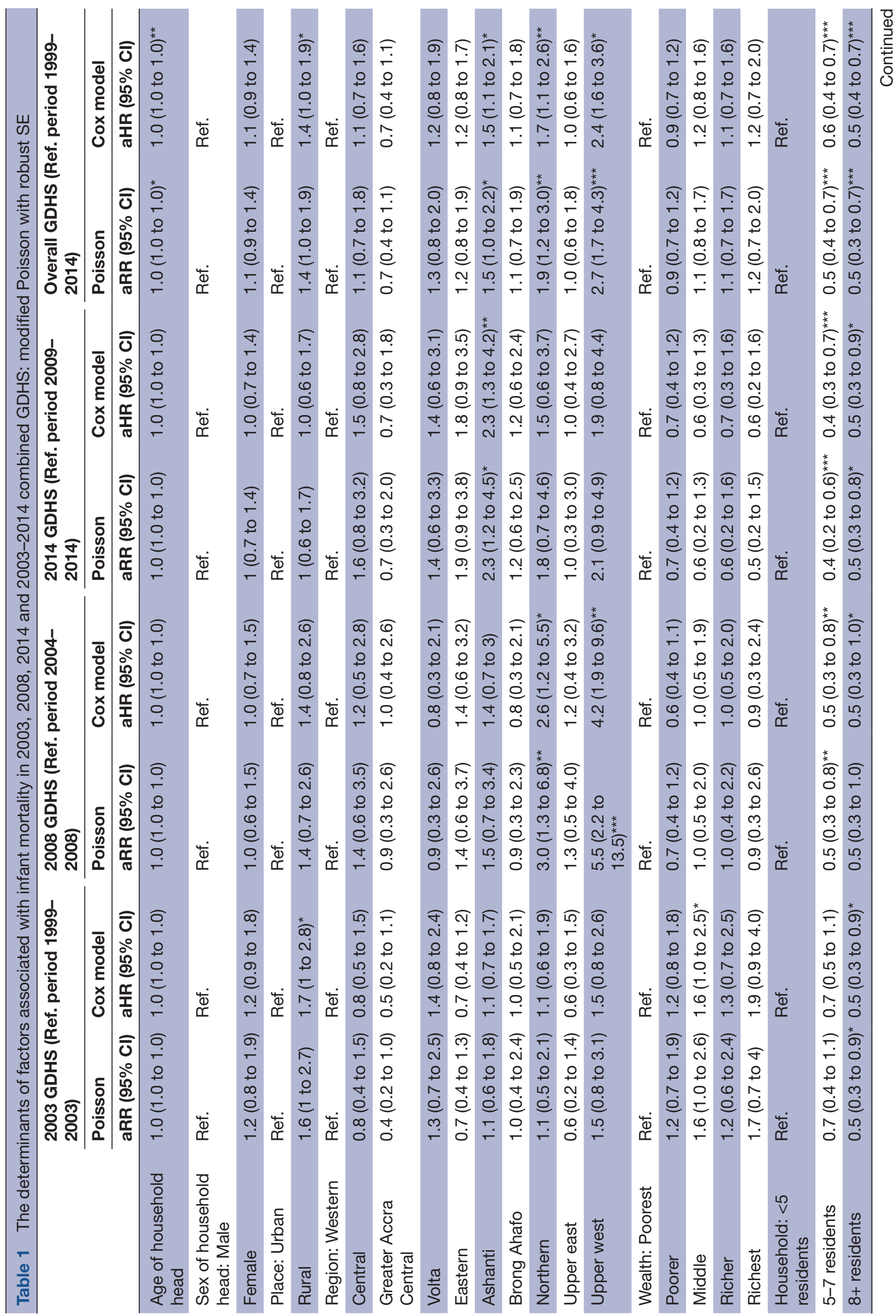




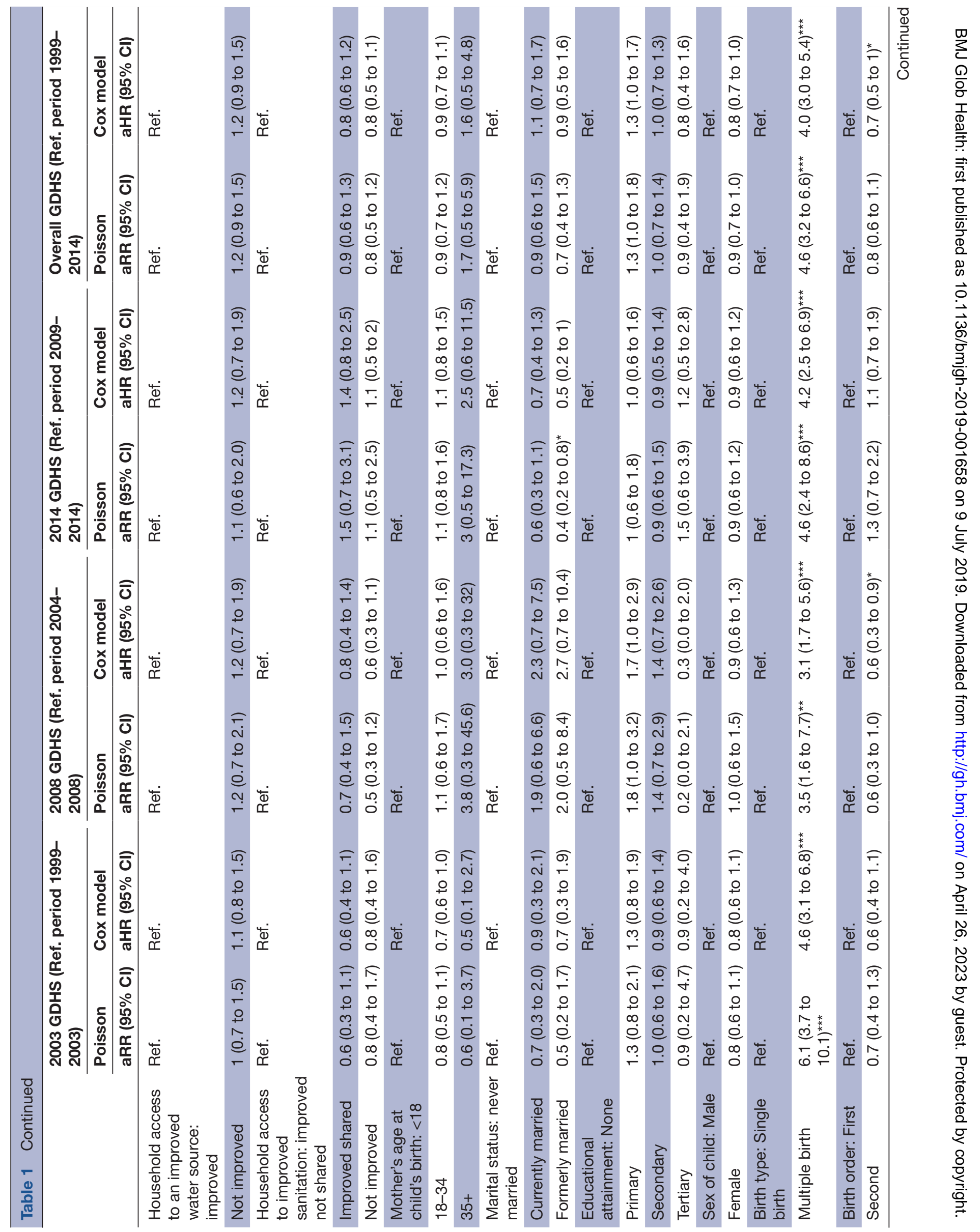




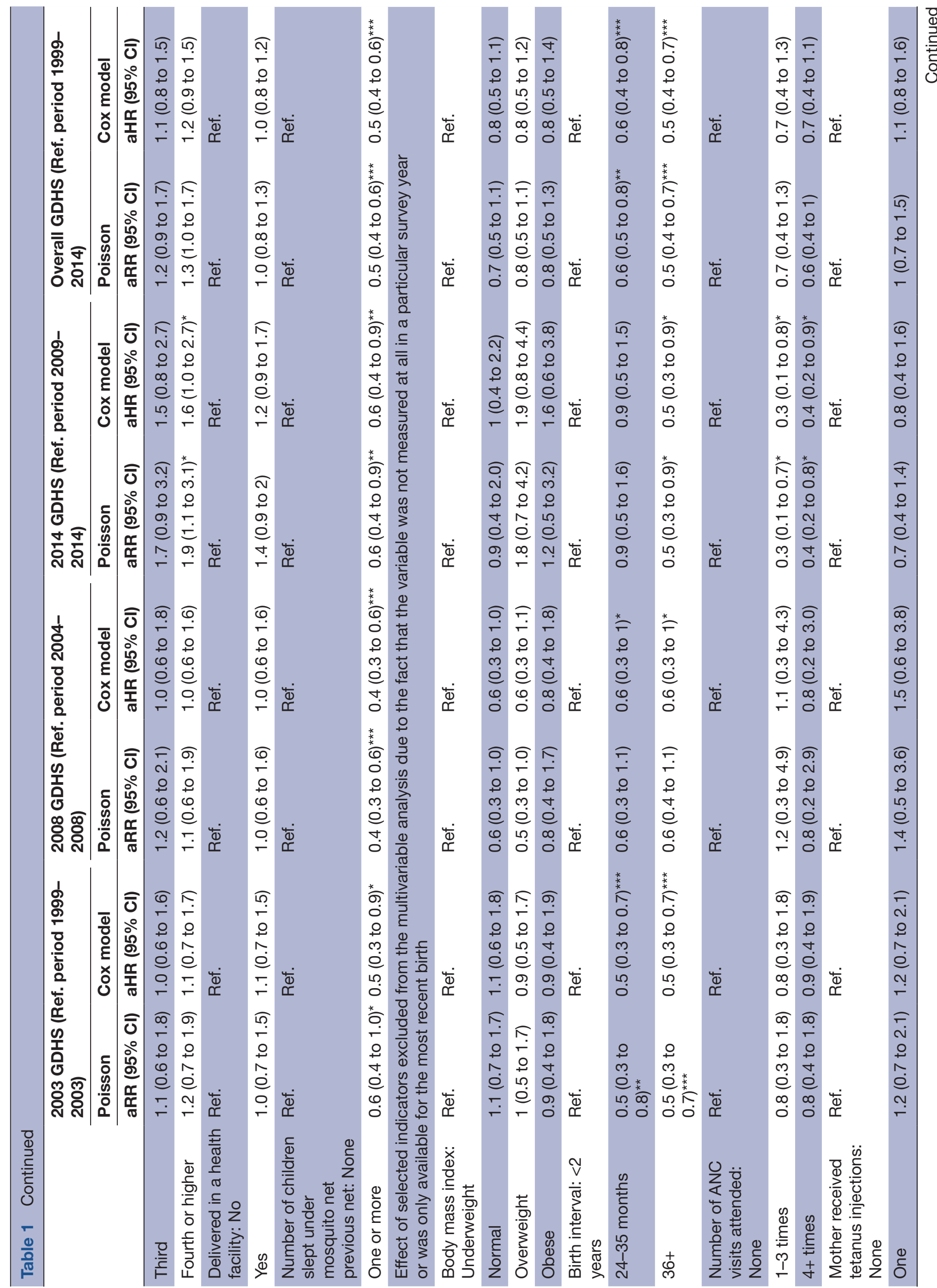

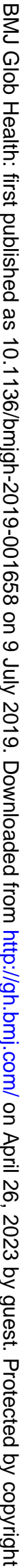




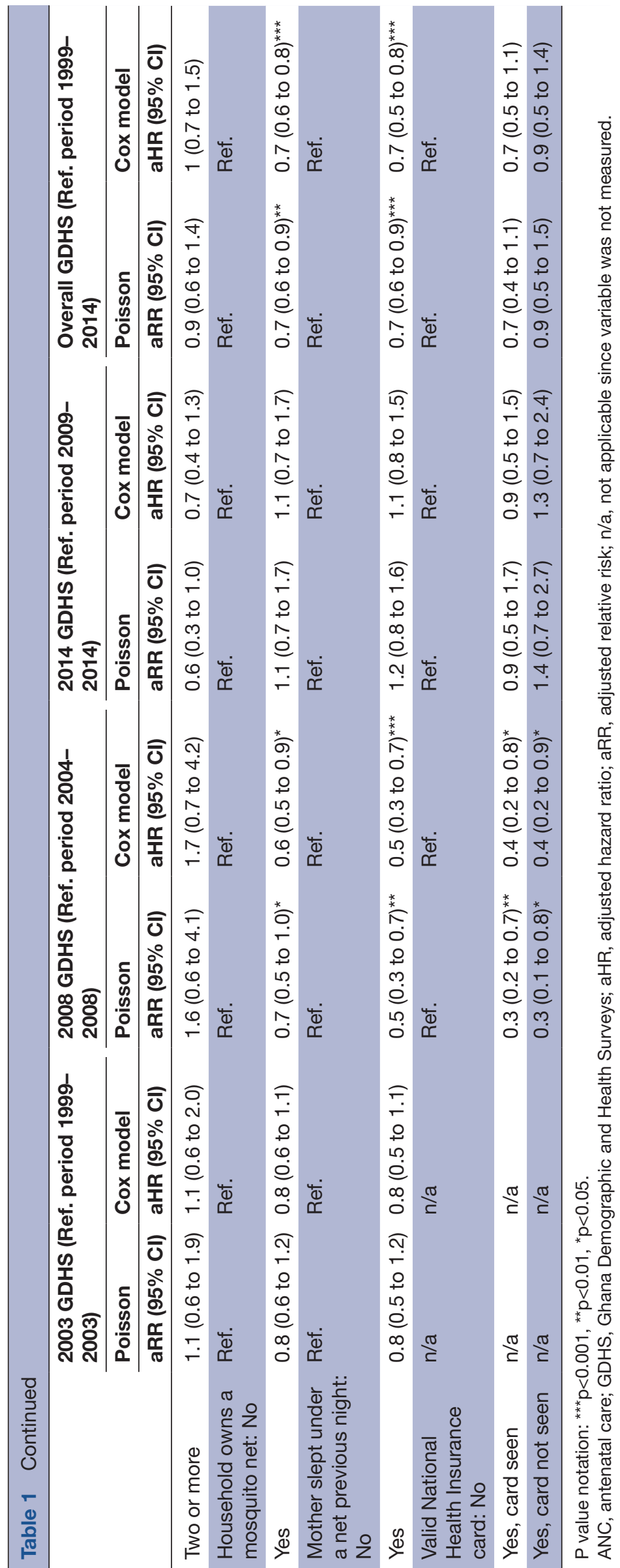




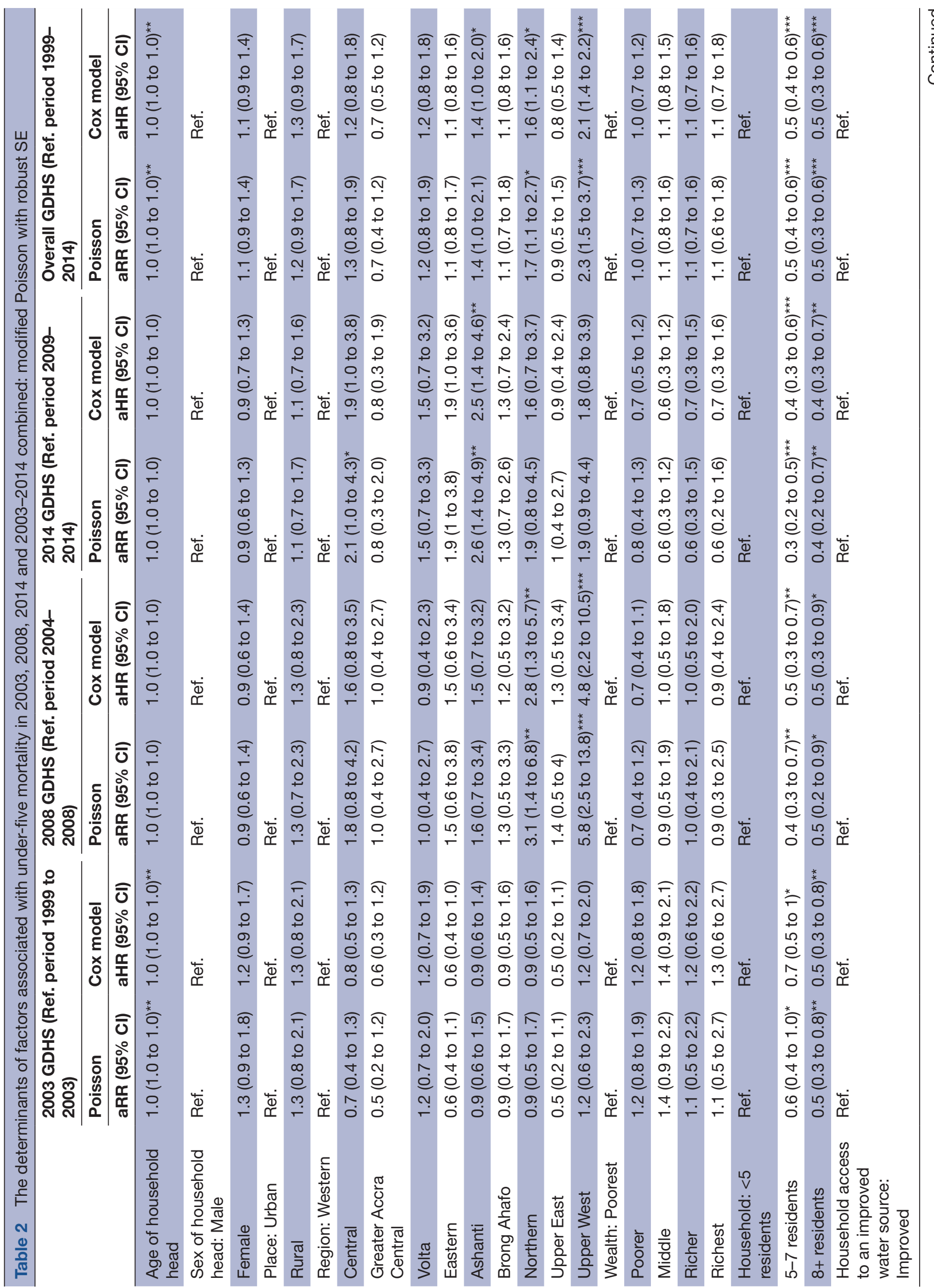




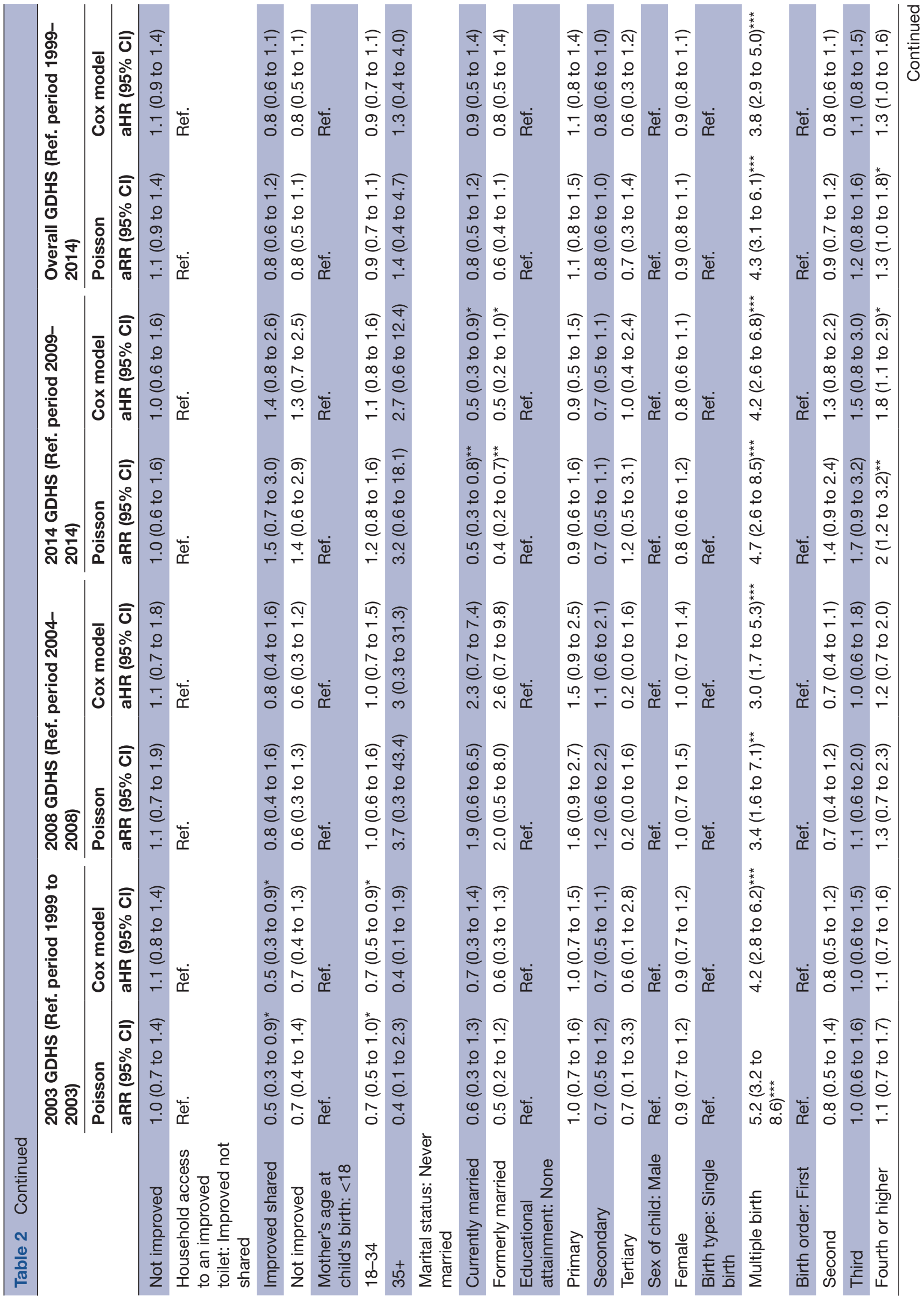




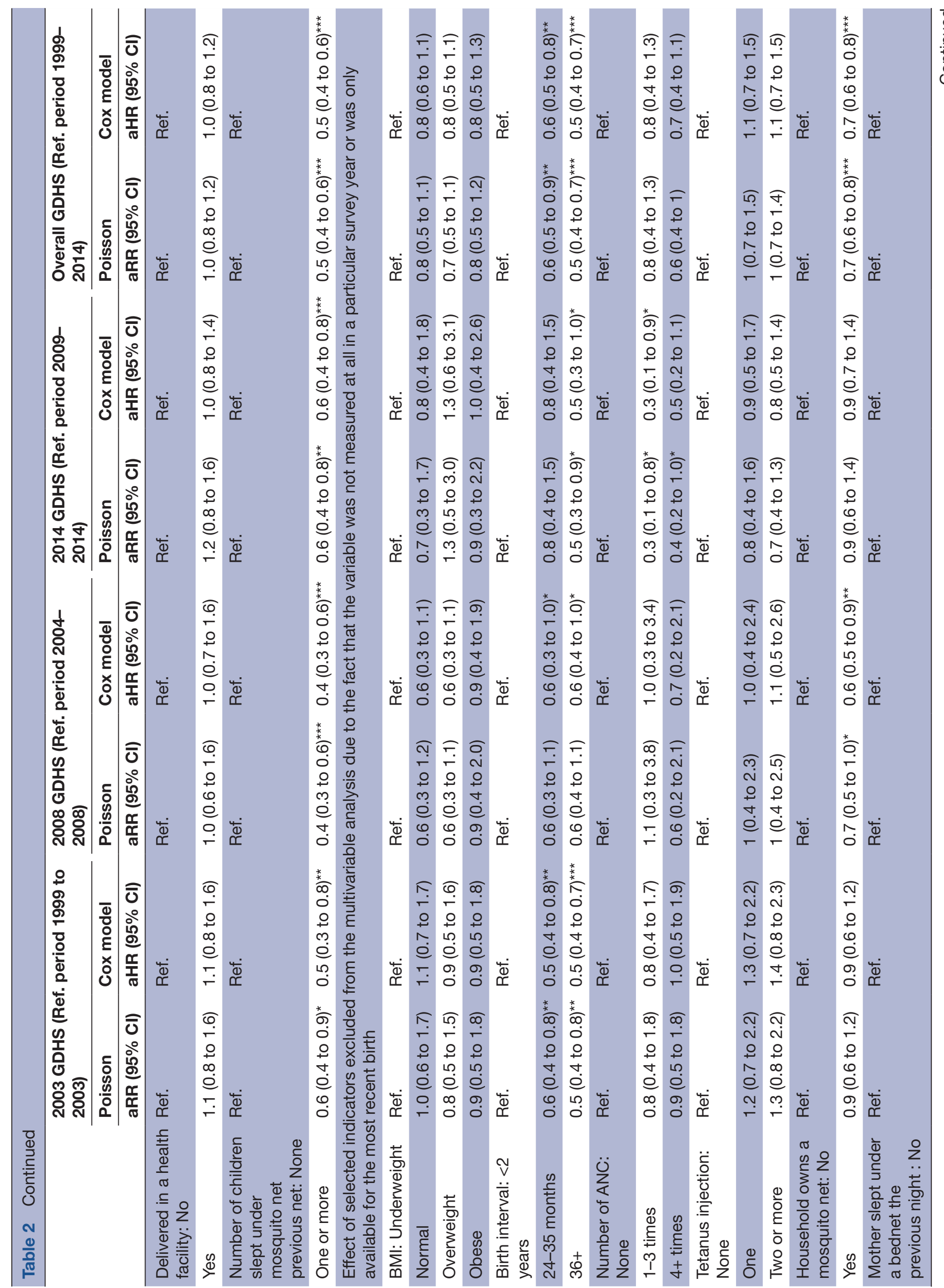




\section{Results on multivariate decomposition}

This section of the analysis identifies which factors are associated with the reduction in the IM and U5M rates between surveys in Ghana. The risk of U5M and IM rates across the surveys were divided into two parts, one representing changes in the distribution of household, mother, or child characteristics, or the coverage of interventions ('endowments'), and the other representing the size of the effect of those characteristics or interventions ('coefficients'). ${ }^{3}$

The 'endowments' column in tables 3 and 4 essentially quantifies the amount of decline in the log rate of infant and under-five mortality explained by the change in coverage in each selected indicator between the two points in time, assuming that the effect of the indicator was constant across the entire period. The 'coefficients' column quantifies the amount of decline in the log rate of infant and under-five mortality explained by the change in effects between the two-time points if coverage (the distribution of each variable) had been constant across the entire period.

The combined effect of all the changes in characteristics or coverage ('endowments') have reduced the log rate IMR by $6.47 \times 10^{-3}(127.6 \%$ decrease, $\mathrm{p}<0.05$; table 3$)$ between 2003 and 2008. By contrast, the combined effect of all coefficients has led to an increase in the log rate of IMR by $1.40 \times 10^{-3}(27.6 \%$ decrease, table 3$)$.

The endowment estimate for 'number of children sleeping under a mosquito net' is ' $-1.7 \times 10^{-3}$ ' indicating that if nothing in the model had changed between the 2003 and 2014 reference periods except the level of children sleeping under a mosquito net, the log rate of IMR would have declined by $1.7 \times 10^{-3}$ points, an amount that is significantly different from zero $(p<0.05$; table 3$)$. However, increased in the proportion of multiple births between 2003 and 2014 was associated with increased in the log rate of infant deaths between 2003 and 2014 by $1.7 \times 10^{-4}$ which is statistically significant $(\mathrm{p}<0.001$; table 3). Change in the percentage of children who slept under-bednet was associated with a significant decline in the log rate of under-five mortality by $2.77 \times 10^{-3}(\mathrm{p}<0.05$; table 3). Detailed results on the decomposition analysis for infant mortality can be found in table 3 .

The combined effect of all the changes in characteristics or coverage of health interventions has reduced the $\log$ rate U5MR by $7.86 \times 10^{-3}(94.2 \%$ decrease, $\mathrm{p}<0.05$; table 4) between 2003 and 2008. The log rate of U5MR reduced by $4.00 \times 10^{-3}$ between 2003 and 2014 as a result of the changes in characteristics or coverage of health interventions (table 4). The combined effect of all the coefficient led to a decrease of $1.06 \times 10^{-2}$ in the log rate of U5MR between 2003 and $2018(73.0 \%$ decrease, $\mathrm{p}<0.05$; table 4). Change in the percentage of children who slept under-bednet was associated with a significant decline in the $\log$ rate of under-five mortality by $2.2 \times 10^{-3}(\mathrm{p}<0.05$; table 4).

Household access to improved sanitation contributed to a $1.29 \times 10^{-3}$ reduction in the $\log$ rate of U5MR between 
Table 3 Multivariate decomposition of household-level, mother-level, child-level and maternal/delivery care and other intervention-related differences in the infant mortality rate (IMR), showing contributions to the IMR gap attributed to differences in endowments and to differences in coefficients, Ghana DHS 2003, 2008 and 2014

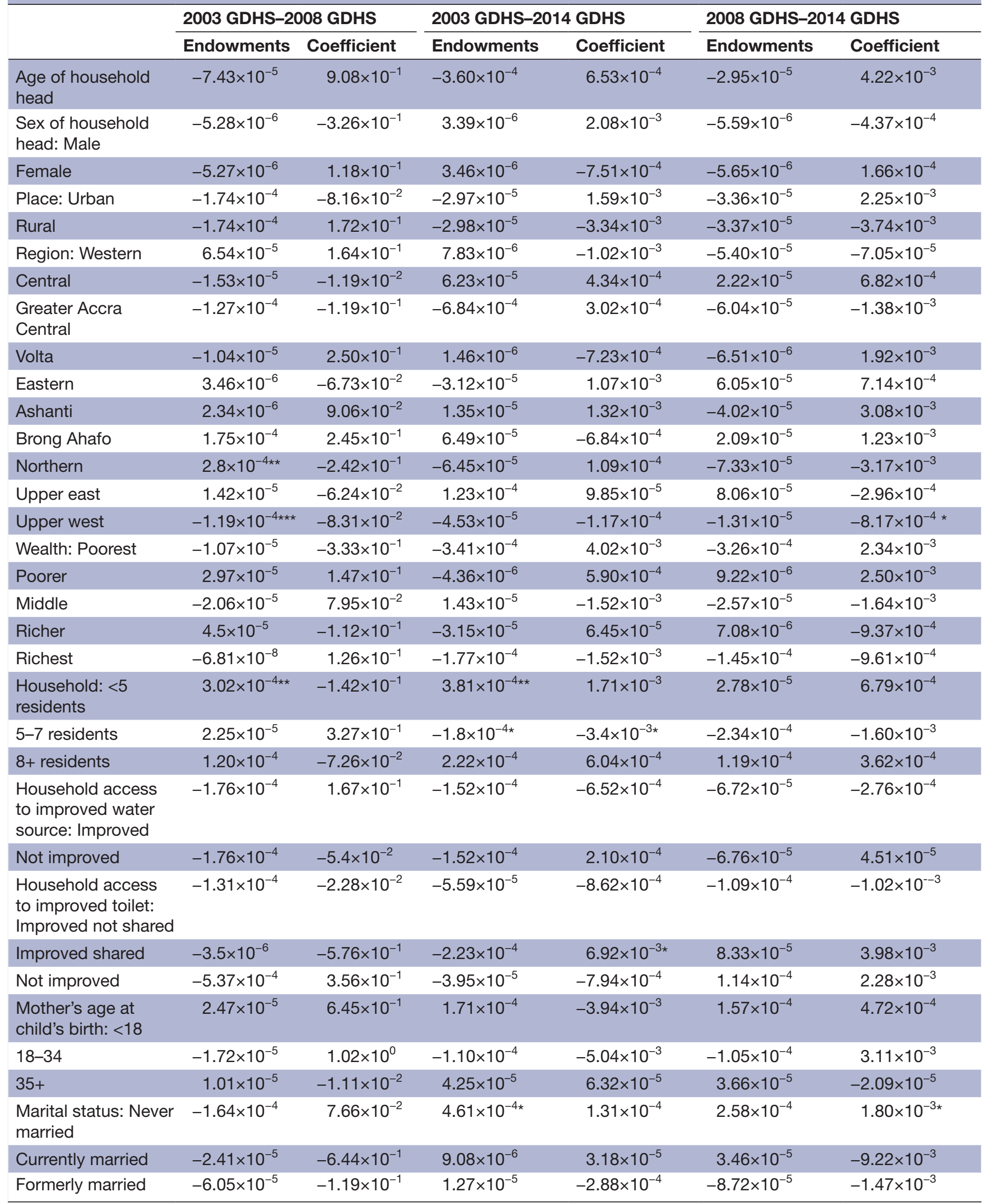


Table 3 Continued

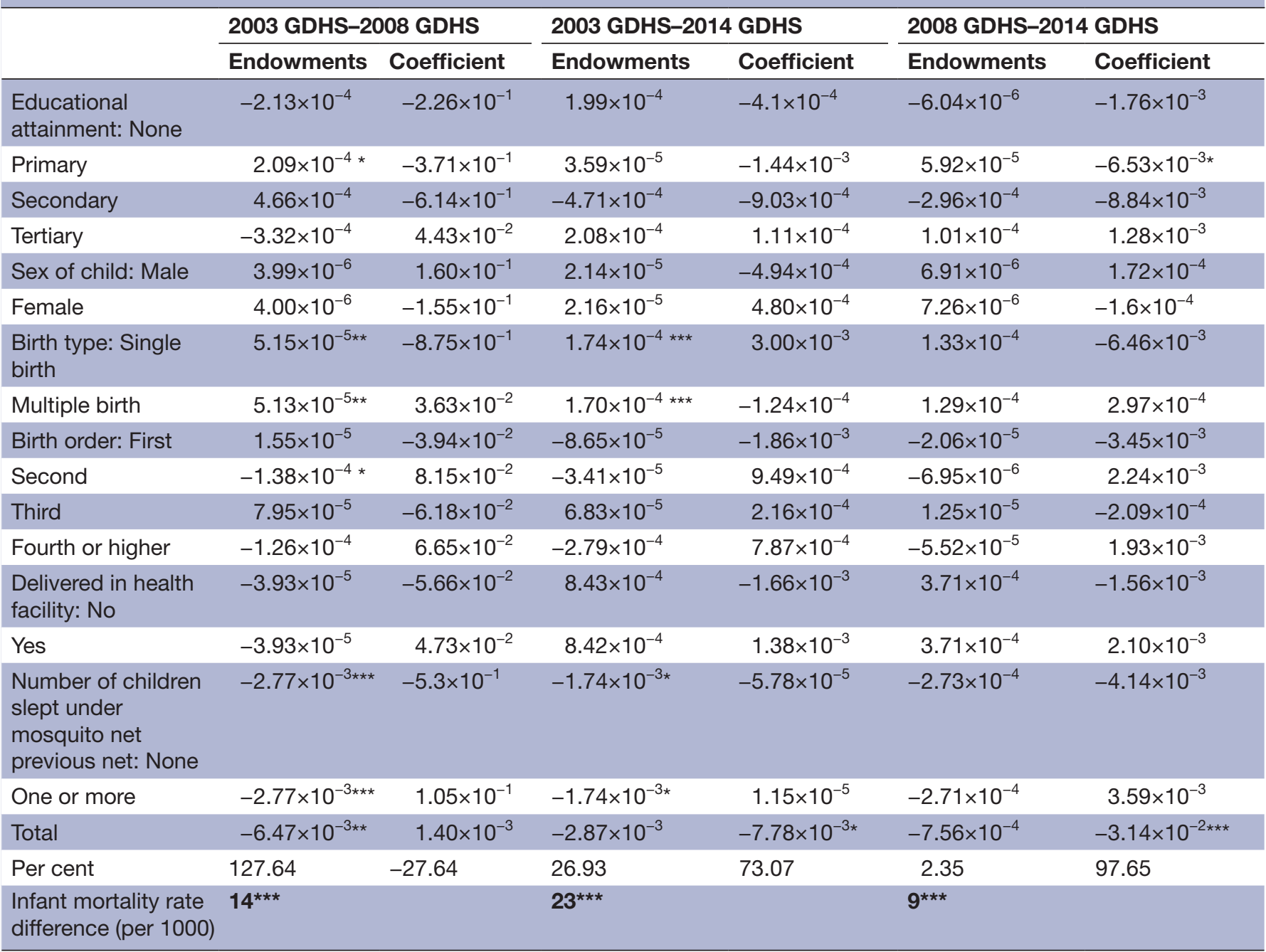

$P$ value notation: ${ }^{* * *} p<0.001,{ }^{* *} p<0.01,{ }^{*} p<0.05$.

GDHS, Ghana Demographic Health Surveys; n/a, not applicable since variable was not measured.

2003 and $2014(\mathrm{p}<0.05$; table 4$)$. However, change in the proportion of multiple births between 2003 and 2014 was associated with increased in the log rate of under-five deaths between 2003 and 2014 by $1.9 \times 10^{-4}$ which was statistically significant $(\mathrm{p}<0.001$; table 4$)$. Detailed results on the decomposition analysis for under-five mortality can be found in table 4 .

\section{Results on country-level factors associated with infant and under-five mortality using penalised regression}

The results from the theory-driven penalisation for LASSO and square root LASSO using covariate dependent penalty level in each case, 10-fold cross-validation LASSO and the LASSO-based extended Bayesian information criteria showed that female labour force participation (FLFP) was the single indicator that was found to be associated with both infant and under-five mortality independent of the type of penalisation applied. A unit increase in the annual percentage of females who are economically active was associated with the reduction of infant mortality by approximately $3-9$ deaths per
1000 annual live births between 2000 and 2018 (table 5). There was a more protective effect of female labour participation relative to under-five mortality. Increasing the annual percentage of female's labour force participation was associated with saving additional 7-18 lives per 1000 live births between 2000 and 2018 (table 5).

\section{DISCUSSION \\ Main findings}

This study investigated the impact of household, maternal and child characteristics and the coverage of key interventions on the risk of infant and under-five deaths in Ghana using data from 2003, 2008 and 2014 DHS. Evidence from the Poisson regression model showed that over the past decade, the household size, multiple births, birth spacing and the number of children sleeping underbednet have been the main driving force of child survival for all children born between 1999 and 2014. Findings from this study indicate that children born with shorter birth intervals ( $\leq 2$ years) were at a greater risk of dying 
Table 4 Multivariate decomposition of household-level, mother-level, child-level, and maternal/delivery care and other intervention-related differences in the under-five mortality rate (U5MR), showing contributions to the U5MR gap attributed to differences in endowments and to differences in coefficients, Ghana DHS 2003, 2008 and 2014

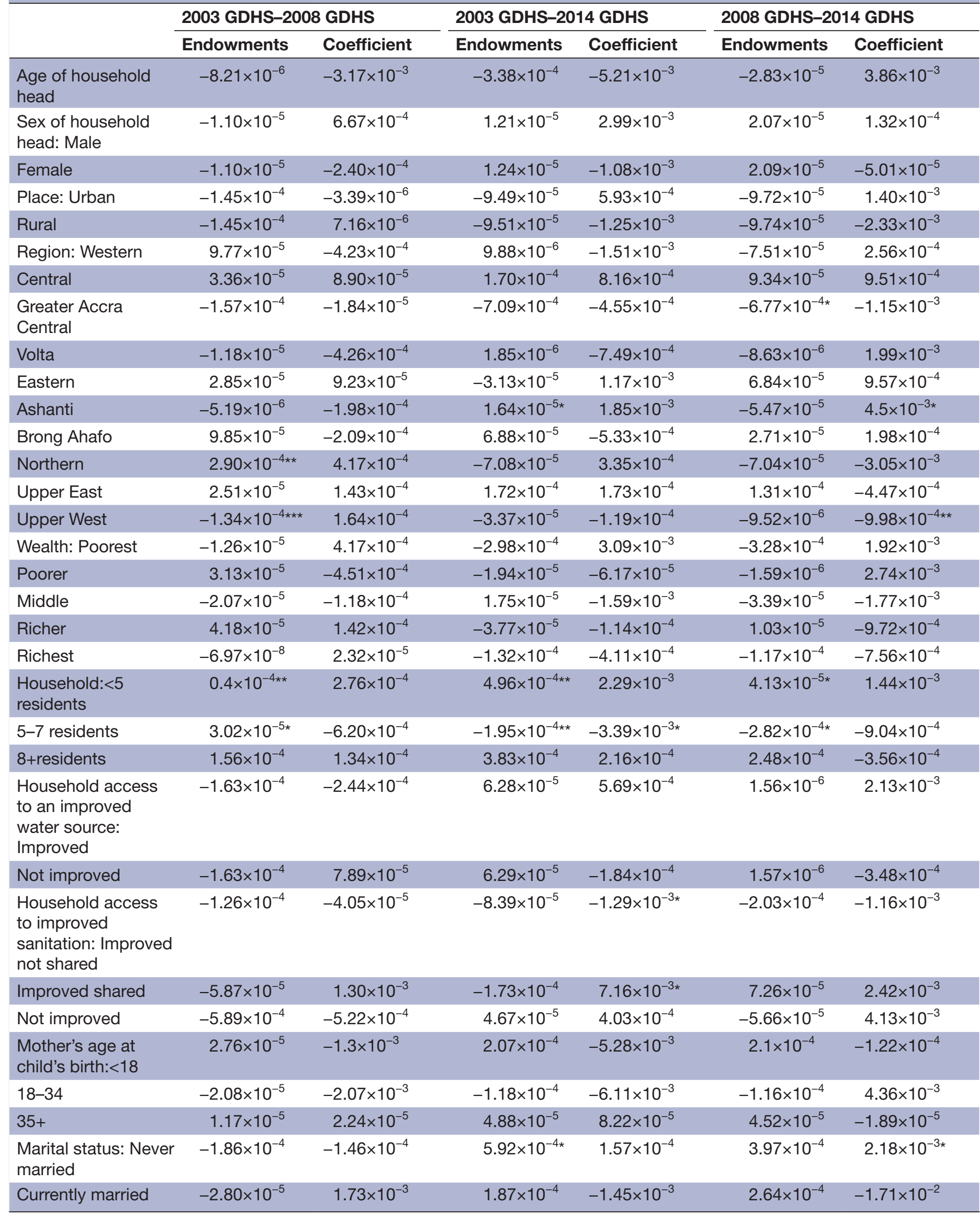


Table 4 Continued

\begin{tabular}{|c|c|c|c|c|c|c|}
\hline & 2003 GDHS-200 & 8 GDHS & 2003 GDHS-201 & 14 GDHS & 2008 GDHS-20 & 4 GDHS \\
\hline & Endowments & Coefficient & Endowments & Coefficient & Endowments & Coefficient \\
\hline Formerly married & $-6.74 \times 10^{-5}$ & $1.90 \times 10^{-4}$ & $1.13 \times 10^{-5}$ & $-2.33 \times 10^{-4}$ & $-7.73 \times 10^{-5}$ & $-1.42 \times 10^{-3}$ \\
\hline $\begin{array}{l}\text { Educational } \\
\text { attainment: None }\end{array}$ & $-4.79 \times 10^{-4}$ & $2.37 \times 10^{-4}$ & $-1.54 \times 10^{-4}$ & $-1.08 \times 10^{-3}$ & $-2.4 \times 10^{-4}$ & $-1.76 \times 10^{-3}$ \\
\hline Primary & $2.48 \times 10^{-4 \star}$ & $7.18 \times 10^{-4}$ & $-2.66 \times 10-7$ & $-1.09 \times 10^{-3}$ & $1.15 \times 10^{-6}$ & $-6.89 \times 10^{-3 \star}$ \\
\hline Secondary & $4.82 \times 10^{-4}$ & $1.14 \times 10^{-3}$ & $-7.69 \times 10^{-4}$ & $-1.09 \times 10^{-3}$ & $-5.86 \times 10^{-4}$ & $-1.03 \times 10^{-2}$ \\
\hline Tertiary & $-4.13 \times 10^{-4}$ & $-7.84 \times 10^{-5}$ & $1.58 \times 10^{-4}$ & $1.19 \times 10^{-4}$ & $6.04 \times 10^{-5}$ & $1.39 \times 10^{-3}$ \\
\hline Sex of Child: Male & $-6.27 \times 10^{-6}$ & $-1.47 \times 10^{-4}$ & $3.23 \times 10^{-5}$ & $7.94 \times 10^{-4}$ & $1.15 \times 10^{-5}$ & $1.64 \times 10^{-3}$ \\
\hline Female & $-6.28 \times 10^{-6}$ & $1.43 \times 10^{-4}$ & $3.27 \times 10^{-5}$ & $-7.71 \times 10^{-4}$ & $1.20 \times 10^{-5}$ & $-1.52 \times 10^{-3}$ \\
\hline $\begin{array}{l}\text { Birth type: Single } \\
\text { birth }\end{array}$ & $5.85 \times 10^{-5 \star *}$ & $1.20 \times 10^{-3}$ & $1.94 \times 10^{-4 \star \star *}$ & $1.09 \times 10^{-3}$ & $1.60 \times 10^{-4 \star \star}$ & $-8.15 \times 10^{-3}$ \\
\hline Multiple birth & $5.83 \times 10^{-5 \star \star}$ & $-4.99 \times 10^{-5}$ & $1.91 \times 10^{-4 \star \star \star}$ & $-4.53 \times 10^{-5}$ & $1.56 \times 10^{-4 \star \star}$ & $3.74 \times 10^{-4}$ \\
\hline Birth order: First & $-1.53 \times 10^{-6}$ & $-3.84 \times 10^{-5}$ & $-1.07 \times 10^{-4}$ & $-2.23 \times 10^{-3}$ & $-3.02 \times 10^{-5}$ & $-3.51 \times 10^{-3}$ \\
\hline Second & $-1.32 \times 10^{-4}$ & $-1.91 \times 10^{-4}$ & $-1.06 \times 10^{-5}$ & $7.96 \times 10^{-4}$ & $-3.71 \times 10^{-6}$ & $2.50 \times 10^{-3}$ \\
\hline Third & $5.21 \times 10^{-5}$ & $8.35 \times 10^{-5}$ & $5.92 \times 10^{-5}$ & $3.60 \times 10^{-4}$ & $1.14 \times 10^{-5}$ & $2.24 \times 10^{-4}$ \\
\hline Fourth or higher & $-2.48 \times 10^{-4}$ & $2.61 \times 10^{-4}$ & $-3.13 \times 10^{-4}$ & $1.43 \times 10^{-3}$ & $-6.85 \times 10^{-5}$ & $5.93 \times 10^{-4}$ \\
\hline $\begin{array}{l}\text { Delivered in health } \\
\text { facility: No }\end{array}$ & $2.27 \times 10^{-5}$ & $1.72 \times 10^{-4}$ & $4.20 \times 10^{-4}$ & $-1.00 \times 10^{-4}$ & $4.00 \times 10^{-5}$ & $1.83 \times 10^{-4}$ \\
\hline Yes & $2.27 \times 10^{-5}$ & $-1.44 \times 10^{-4}$ & $4.20 \times 10^{-4}$ & $8.37 \times 10^{-5}$ & $3.99 \times 10^{-5}$ & $-2.47 \times 10^{-4}$ \\
\hline $\begin{array}{l}\text { Number of children } \\
\text { slept under } \\
\text { mosquito net } \\
\text { previous net: None }\end{array}$ & $-3.37 \times 10^{-3 \star \star \star}$ & $9.16 \times 10^{-4}$ & $-2.16 \times 10^{-3 * *}$ & $1.16 \times 10^{-4}$ & $-3.74 \times 10^{-4 *}$ & $-4.26 \times 10^{-3}$ \\
\hline One or more & $-3.37 \times 10^{-3 \star \star \star}$ & $-1.82 \times 10^{-4}$ & $-2.16 \times 10^{-3 * \star}$ & $-2.30 \times 10^{-5}$ & $-3.73 \times 10^{-4 \star}$ & $3.69 \times 10^{-3}$ \\
\hline Total & $-7.86 \times 10^{-3 \star \star}$ & $-4.83 \times 10^{-4}$ & $-4.00 \times 10^{-3 *}$ & $-1.06 \times 10^{-2 \star \star}$ & $-1.84 \times 10^{-3 \star}$ & $-3.44 \times 10^{-2 \star \star \star}$ \\
\hline Percent & 94.22 & 5.78 & 27.43 & 72.57 & 5.09 & 94.92 \\
\hline $\begin{array}{l}\text { Under-five Mortality } \\
\text { Rate difference (per } \\
1,000 \text { ) }\end{array}$ & $31^{\star \star \star}$ & & $51^{* \star *}$ & & $20^{\star \star \star}$ & \\
\hline
\end{tabular}

$P$ value notation: ${ }^{* * *} p<0.001,{ }^{* *} p<0.01,{ }^{*} p<0.05$.

DHS, Demographic and Health Surveys; GDHS, Ghana Demographic and Health Surveys.

before the first birthday and this result is consistent with a similar study by Ezeh $e t a l^{24}$ and Setty-Venugopal et $a l^{25}$

Country-level analysis using penalised regression technique identified FLFP as an important indicator associated with both infant and under-five mortality. The multivariate decomposition analysis revealed that the changes in the prevalence of some selected indicators especially household size, multiple births and the number of children sleeping under-bednet contributed significantly to the change in both infant and under-five mortality between 2003-2008 and 2003-2014.

\section{Relationship between multiple births and child mortality}

The risk of infant death among multiple births was relatively high for each independent survey data set that was analysed. The finding is consistent with several studies in the medical literature. ${ }^{2627}$ Multiple births are classified among high-risk pregnancies and births, especially in developing countries where the healthcare system is faced with challenges of providing basic public health and maternal and child healthcare to their population. ${ }^{28} 29$

Trend analysis by Smith $e t a l^{30}$ has shown that most deaths among multiples occurred in the first 28 days of life indicating that the higher mortality rate for multiple births may be partly due to pregnancy or birth-related factors. For instance, multiples are more likely to have fetal heart rate abnormalities, born prematurely, have intrauterine growth restriction and congenital abnormalities, weigh less at birth and more likely to have complications around the time of labour and delivery, such as umbilical cord prolapse or premature separation of the placenta as reported by the England National Health System (https://www.nhs.uk/). A more worrisome effect of multiple births in Ghana as observed in this study is the fact that the impact is not declining over time. 
Table 5 Country-level factors associated with infant and under-five mortality rates in Ghana using penalised regression $L_{1}$ penalisation: $\mathbf{L}$

\begin{tabular}{|c|c|c|c|c|}
\hline & & & & \\
\hline & $\begin{array}{l}\text { Rigorous } \\
\text { theory-driven } \\
\text { penalisation } \\
\text { for LASSO } \\
\text { using covariate } \\
\text { dependent penalty } \\
\text { level }\end{array}$ & $\begin{array}{l}\text { Rigorous } \\
\text { theory-driven } \\
\text { penalisation } \\
\text { for square } \\
\text { root LASSO } \\
\text { using covariate } \\
\text { dependent penalty } \\
\text { level }\end{array}$ & $\begin{array}{l} \\
\text { ten folds cross- } \\
\text { validation LASSO } \\
\end{array}$ & $\begin{array}{l}\text { LASSO based } \\
\text { on extended } \\
\text { Bayesian } \\
\text { information } \\
\text { criteria }\end{array}$ \\
\hline \multicolumn{5}{|c|}{ Country-level factors influencing infant-five mortality rate in Ghana } \\
\hline Internet use & -0.15 & & -0.10 & -0.10 \\
\hline Female labour force participation & -9.31 & -7.88 & -3.73 & -4.42 \\
\hline Birth rate & & 2.30 & & \\
\hline Government effectiveness & & & 0.71 & 0.79 \\
\hline Tuberculosis & & & 0.06 & 0.05 \\
\hline Access to electricity & & & -0.01 & \\
\hline Access to drinking water-rural & & & -0.80 & -0.77 \\
\hline Government effectiveness & & & 0.71 & \\
\hline Prevalence of HIV & & & 0.92 & \\
\hline Urban Population & & & -0.45 & -0.49 \\
\hline Government expenditure on education & & & -0.03 & -0.01 \\
\hline \multicolumn{5}{|c|}{ Country-level factors influencing the under-five mortality rate in Ghana } \\
\hline Internet use & -0.23 & & -0.07 & -0.18 \\
\hline Female labour force participation & -17.54 & -14.56 & -16.29 & -6.53 \\
\hline Birth rate & & 4.38 & 2.47 & \\
\hline Government effectiveness & & & 0.86 & 1.14 \\
\hline Tuberculosis & & & & 0.10 \\
\hline Access to electricity & & & & -0.01 \\
\hline Access to drinking water-rural & & & & -1.41 \\
\hline Government effectiveness & & & & 1.14 \\
\hline Prevalence of HIV & & & & 1.62 \\
\hline Urban population & & & & -0.79 \\
\hline Government expenditure on education & & & & -0.04 \\
\hline
\end{tabular}

Parameter estimates were based on 25 selected country-level covariates. Details of the covariates studied can be found in online supplementary S8.

LASSO, Least Absolute Shrinkage and Selection Operator.

\section{Relationship between birth spacing and child mortality}

The bivariate analysis of birth spacing and mortality showed that a preceding birth interval of fewer than 24 months was associated with a three to a sixfold increase in infant mortality risk although the effect size estimate was unadjusted because the survey measured birth interval for most recent birth. Although the negative effect was found to be consistent over time (2003, 2008 and 2014), the results should be interpreted with caution. Nonetheless, our finding was consistent with previous studies conducted in lower and middle income countries. ${ }^{31} 32$ The relationship between birth spacing and child survival could be explained by the fact that women with shorter birth spacing have a higher risk of pre-eclampsia, high blood pressure and premature rupture of membranes compared with those with an interval of $27-50$ months. ${ }^{32}$

\section{Effect of sleeping under bednet and child mortality}

This study found that increasing the number of children that sleep under bednet was associated with the reduction of infant and U5MRs over the period. The impact of insecticide-treated bednet in reducing malaria incidence and all-cause child mortality has been well documented in the literature. ${ }^{33-35}$ Ghana is among the countries in SSA that have benefited from the US President Malaria Initiative (PMI) since 2007 and the Global Fund in 2003 up until. The goal of these two major policy initiative is to decrease the incidence of malaria and malaria-related morbidity and mortality to the barest minimum through 
the distribution long-lasting insecticide-treated bednet, indoor residual spraying and intermittent preventive treatment of malaria for pregnant women.

\section{Impact of female labour force participation on child mortality}

FLFP was associated with the reduction of both infant and U5MR. The inverse relationship between FLFP and child survival is consistent with a more recent study in Nigeria ${ }^{36}$ but contrast similar studies conducted in Nepal. ${ }^{3738}$ Authors that found a negative impact of FLFP explained that mothers who are economically active and hold certain key positions in society may not have time for their children exposing them to series of life-threatening diseases and other environmental hazards. ${ }^{39}$

On the contrary, mothers who are in the active labour force are more empowered with higher decision-making and have the financial muscle to pay for childcare support in her absence, provide basic healthcare in times of need, and provide nutritious food and improved sanitation and access to clean water for her children thereby reducing the risk of death. ${ }^{40}$ The level of disagreement among different authors on the impact FLFP in medical literature requires a more rigorous study design to determine the full benefit of FLFP on child survival.

\section{Relationship between household size and child mortality}

The observed protective effect of household size may not necessarily be the size of the household but the benefit of having more educated and experience household members to advice on critical child and maternal healthcare challenges. More research needs to be done to better understand the dynamics of household size and its relative effect on child survival in Ghana.

\section{Strengths and limitations of the study}

The use of 2003, 2008 and 2014 versions of the GDHS increase the sample size and the power of the study. Performing survey specific and pooled analysis allowed us to determine factors that have been consistent in affecting child survival in the last decade. The GDHS is a well-designed nationally representative survey with an average response rate of $97 \%$. Second, the used of Poisson based decomposition analysis allowed us to determine factors contributing to the decline in child mortality between two specific surveys. Application of more rigorous penalised regression technique allowed us to determine the effect of several country-level factors associated with child mortality despite the high dimensional nature of the data and its related problems like over-fitting model complexity and multicollinearity.

Our study, however, has some limitations. First, the use of secondary data prevented us from including in our different model's other factors that were more likely to be associated with early neonatal deaths such as pregnancy-induced hypertension, gestational age of the fetus in weeks, antepartum haemorrhage, diabetes, eclampsia, history of previous stillbirth, history of neonatal death, weight of mother at registration, haemoglobin at registration, malaria intermittent preventive treatment doses for pregnant women and premature rapture membrane, environmental and genetic factors. These factors are equally important and should not be overlooked when implementing interventions to reduce child mortality. Finally, most cross-sectional studies are subject to recall bias and are more difficult to use data that originate from surveys to establish causality since both the exposure and the outcome measures are determined at the same time.

\section{Policy implications}

Our findings indicate the need to assign more qualified medical personnel to the rural areas of Ghana to address the menace of multiple births. There should be regular training for health professionals based on clearly defined policy on multiple births delivery and how the policy document will guide health professionals to reduce the risk of child mortality associated with multiple births. The scheduled training regimen may include but not limited to nutrition requirement for mothers carrying multiple pregnancies, more frequent prenatal visits, maternal and fetal testing, cervical cerclage, corticosteroid medications, and tocolytic medications. To reduce the burden of multiple births related to mortality, women carrying multiple births should be educated on how to manage multiple pregnancies.

Postpartum family planning could also be encouraged to minimise multiple pregnancies. The monitoring of fetal growth during ANC attendance will give healthcare providers the opportunity for increased surveillance of these high-risk groups especially intensive care of multiple births is likely to be very important during the first month of life. ${ }^{41}$ WHO recommendation on antenatal corticosteroid therapy for women at risk preterm birth with a single or multiple pregnancies should be adhered to by health professionals.

The $\mathrm{MOH}$ and the GHS should empower and use the media (radio, television and social media), community health workers and other healthcare professionals to provide intensive education about child spacing and contraceptive use by mothers. The Government of Ghana and foreign partners (PMI, Global Fund, USAID, etc.) should endeavour to sustain the gains made in the reduction of child mortality by increasing coverage of bednet use among children and pregnant women and intensify education on malaria preventive measures. Specific interventions that are likely to increase FLFP such as Savannah Accelerated Development Authority, Planting for Food and Jobs and Livelihood Empowerment Against Poverty programme should be enhanced and scale-up to meet the growing female population.

\section{CONCLUSIONS}

The analysis of the individual surveys and the pooled data analysis of the 2003, 2008 and 2014 GDHS data sets showed that multiple births and shorter birth interval have an 
adverse effect on child survival in Ghana. However, the increase in FLFP and increase in household ownership and the use of bednet were the three main indicators associated with the reduction in child mortality in Ghana between 2003 and 2014. We observed that some regions have a significantly elevated risk. Future studies could employ Geospatial modelling technique to understand the heterogeneity in space and time to further improve policy and decision making relative to the geographical location.

\section{Author affiliations \\ 'Department of Biostatistics, School of Public Health, College of Health Sciences, University of Ghana, Legon, Ghana \\ ${ }^{2}$ Department of Physician Assistantship, School of Medicine and Health Sciences, Central University College, Accra, Ghana \\ ${ }^{3}$ Department of Biostatistics, School of Public Health, College of Health Sciences, University of Ghana, Accra, Ghana \\ ${ }^{4}$ Department of Management Science, School of Business, Ghana Institute of Management and Public Administration, Accra, Ghana \\ ${ }^{5}$ Department of Community Health, School of Public, College of Health Sciences, University of Ghana, Accra, Ghana}

Acknowledgements The authors duly acknowledge the Demographic and Health Survey Program funded by the U.S. Agency for International Development (USAID), other donors and Ghana Statistical Service for making their data available to the public. We do acknowledge all mothers that were interviewed.

Contributors All authors contributed significantly to this manuscript and met the authorship criteria set out for the BMJ Global Health.

This research received no specific grant from any funding agency in the public, commercial or not-for-profit sectors.

Competing interests No, there are no competing interests for any author.

Ethics approval This study involves the analysis of anonymous publicly available secondary data and therefore no ethical approval was required.

Provenance and peer review Not commissioned; externally peer reviewed.

Data availability statement Data are available in a public, open access repository.

Open access This is an open access article distributed in accordance with the Creative Commons Attribution Non Commercial (CC BY-NC 4.0) license, which permits others to distribute, remix, adapt, build upon this work non-commercially, and license their derivative works on different terms, provided the original work is properly cited, appropriate credit is given, any changes made indicated, and the use is non-commercial. See: http://creativecommons.org/licenses/by-nc/4.0/.

\section{REFERENCES}

1. United-Nations. United Nations Millennium Declaration: New York: United Nations. Secondary United Nations Millennium Declaration: New York: United Nations; 2000.

2. The, Global, Economy. Economic indicators for over 200 countries Secondary Economic indicators for over 200 countries, 2019. Available: www.globaleconomy.com

3. Winter R, Pullum T, Langston A, et al. Trends in neonatal mortality in Rwanda 2000-2010. Further analysis of the Rwanda Demographic and Health Surveys 2013.

4. Kayode GA, Ansah E, Agyepong IA, et al. Individual and community determinants of neonatal mortality in Ghana: a multilevel analysis. BMC Pregnancy Childbirth 2014;14:165.

5. Gyimah SO. Ethnicity and infant mortality in sub-Saharan Africa: The case of Ghana. PSC Discussion Papers Series 2002;16.

6. Lambon-Quayefio MP, Owoo NS. Examining the influence of antenatal care visits and skilled delivery on neonatal deaths in Ghana. Appl Health Econ Health Policy 2014;12:511-22.

7. Babayara MNK, Addo B. Risk Factors for Child Mortality in the Kassena-Nankana District of Northern Ghana: A Cross-Sectiona Study Using Population-Based Data. Scientifica 2018;2018:1-7.
8. Osei-Kwakye K, Otupiri E, Owusu Dabo E, et al. Determinants of under-five mortality in Builsa District, upper east region, Ghana. Journal of Science and Technology 2010;30.

9. Kanmiki EW, Bawah AA, Agorinya I, et al. Socio-economic and demographic determinants of under-five mortality in rural northern Ghana. BMC Int Health Hum Rights 2014;14:24.

10. Tette EMA, Nyarko MY, Nartey ET, et al. Under-five mortality pattern and associated risk factors: a case-control study at the Princess Marie Louise Children's Hospital in Accra, Ghana. BMC Pediatr 2016:16:148.

11. Tette EMA, Neizer M, Nyarko MY, et al. Changing Patterns of Disease and Mortality at the Children's Hospital, Accra: Are Infections Rising? PLoS One 2016;11:e0150387.

12. Welaga $\mathrm{P}$, Moyer $\mathrm{CA}$, Aborigo R, et al. Why are babies dying in the first month after birth? A 7-year study of neonatal mortality in northern Ghana. PLoS One 2013;8:e58924.

13. Dorofeev S, Grant P. Statistics for real-life sample surveys: Nonsimple-random samples and weighted data. Cambridge University Press, 2006.

14. Kaminska O, Lynn P. Survey-based cross-country comparisons where countries vary in sample design: issues and solutions. J Off Stat 2017;33:123-36.

15. GSS G, Service GS. (GSS), Ghana Health Service (GHS), and ICF Macro. 2008. Accra: Ghana Demographic and Health Survey, 2009.

16. Mosley WH, Chen LC. An analytical framework for the study of child survival in developing countries. Popul Dev Rev 1984;10:25-45.

17. Kipp AM, Blevins M, Haley CA, et al. Factors associated with declining under-five mortality rates from 2000 to 2013: an ecological analysis of 46 African countries. BMJ Open 2016;6:e007675.

18. OurWorldinData. World Population Growth 2017.

19. Powers DA, Yoshioka H, Yun M-S. mvdcmp: Multivariate decomposition for nonlinear response models. Stata $J$ 2011:11:556-76.

20. Oaxaca R. Male-female wage differentials in urban labor markets. Int Econ Rev 1973;14:693-709.

21. Belloni A, Chernozhukov V, Hansen C, et al. Inference in highdimensional panel models with an application to gun control. J Bus Econ Stat 2016;34:590-605

22. Tibshirani R. Regression shrinkage and selection via the lasso. $J$ Royal Stat Soc B 1996;58:267-88

23. Ahrens A, Hansen CB, Schaffer ME. lassopack: Model selection and prediction with regularized regression in Stata, 2019. Available: https://arxiv.org/abs/1901.05397

24. Ezeh OK, Agho KE, Dibley MJ, et al. Risk factors for postneonatal, infant, child and under-5 mortality in Nigeria: a pooled crosssectional analysis. BMJ Open 2015;5:e006779.

25. Setty-Venugopal V, Upadhyay UD. Birth spacing: three to five saves lives. Population Reports Series L: Issues in World Health 2002;13:1-23.

26. Hong R. Effect of multiple birth on infant mortality in Bangladesh. $J$ Paediatr Child Health 2006;42:630-5.

27. Uthman OA, Uthman MB, Yahaya I. A population-based study of effect of multiple birth on infant mortality in Nigeria. BMC Pregnancy Childbirth 2008;8:41.

28. Atiyeh GN, El-Mohandes A. Preventive healthcare of infants in a region of Lebanon: parental beliefs, attitudes and behaviors. Matern Child Health J 2005;9:83-90.

29. Bryce J, Black RE, Walker N, et al. Can the world afford to save the lives of 6 million children each year? The Lancet 2005;365:2193-200.

30. Smith LK, Manktelow BN, Draper ES, et al. Trends in the incidence and mortality of multiple births by socioeconomic deprivation and maternal age in England: population-based cohort study. BMJ Open 2014;4:e004514.

31. Fotso JC, Cleland J, Mberu B, et al. Birth spacing and child mortality: an analysis of prospective data from the Nairobi urban health and demographic surveillance system. J Biosoc Sci 2013;45:779-98

32. van Soest A, Saha UR. Relationships between infant mortality, birth spacing and fertility in Matlab, Bangladesh. PLoS One 2018:13:e0195940.

33. Jakubowski A, Stearns SC, Kruk ME, et al. The US President's Malaria Initiative and under- 5 child mortality in sub-Saharan Africa: A difference-in-differences analysis. PLOS Med 2017;14:e1002319.

34. Fegan GW, Noor AM, Akhwale WS, et al. Effect of expanded insecticide-treated bednet coverage on child survival in rural Kenya: a longitudinal study. The Lancet 2007;370:1035-9.

35. Atieli HE, Zhou G, Afrane Y, et al. Insecticide-treated net (ITN) ownership, usage, and malaria transmission in the highlands of western Kenya. Parasit Vectors 2011;4.

36. Ovikuomagbe-Oyedele. Child mortality and female labour participation in Nigeria. Int J Econ Res 2017;V8 i5:74-84. 
37. Ghosh A, Singh A, Chigateri S. A Trapeze Act: women balancing paid work and unpaid care work in Nepal 2017.

38. Timilsina K, Sawangdee $Y$, Hunchangsith $P$, et al. Female labor force participation, paid maternity, caste system and under-5 mortality in Nepal. J Health Res 2019;33:57-67.

39. Siah AKL, Lee GHY. Female labour force participation, infant mortality and fertility in Malaysia. J Asia Pac Econ 2015;20:613-29.
40. Nandi A, Hajizadeh M, Harper S, et al. Increased duration of paid maternity leave lowers infant mortality in low- and middleincome countries: a quasi-experimental study. PLoS Med 2016;13:e1001985.

41. Imaizumi Y. Infant mortality rates in single, twin and triplet births, and influencing factors in Japan, 1995-98. Paediatr Perinat Epidemiol 2001;15:346-51. 